Supplementary Information

\title{
Mechanistic Insight and Optimization of InP Nanocrystals Synthesized with Aminophosphines
}

\author{
Aude Buffard ${ }^{\dagger \S}$, Sébastien Dreyfuss ${ }^{\ddagger \S}$, Brice Nadal $^{\dagger}$, Hadrien Heuclin ${ }^{\dagger}$, Xiangzhen Xu $^{\dagger}$, Gilles
}

Patriarche $^{\delta}$, Nicolas Mézailles ${ }^{{ }^{*}}$, Benoit Dubertret ${ }^{+*}$

\footnotetext{
' Laboratoire de Physique et d'Etude des Matériaux, ESPCI-ParisTech, PSL Research University, Sorbonne Université UPMC Univ. Paris 06, CNRS, 10 rue Vauquelin 75005 Paris, France

‡Laboratoire Hétérochimie Fondamentale et Appliquée CNRS, Université Paul Sabatier, 118 route de Narbonne, 31062 Toulouse

${ }^{\delta}$ Laboratoire de Photonique et Nanostructure, CNRS, Université Paris-Saclay, Route de Nozay, 91460 Marcoussis

$\S$ These authors have contributed equally to this work

*mezailles@chimie.ups-tlse.fr, *benoit.dubertret@espci.fr
}

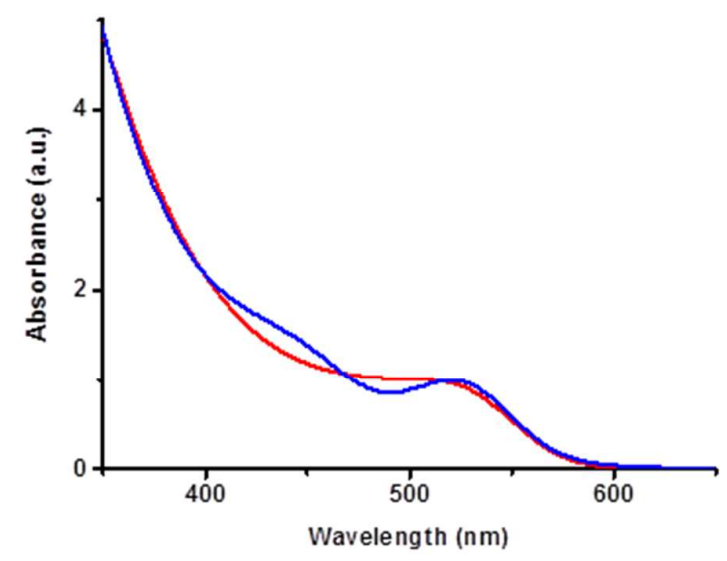

Figure S1. Absorbance spectra of InP QDs synthesis with (blueline) and without (redline) addition of $\mathrm{ZnCl}_{2}$. 


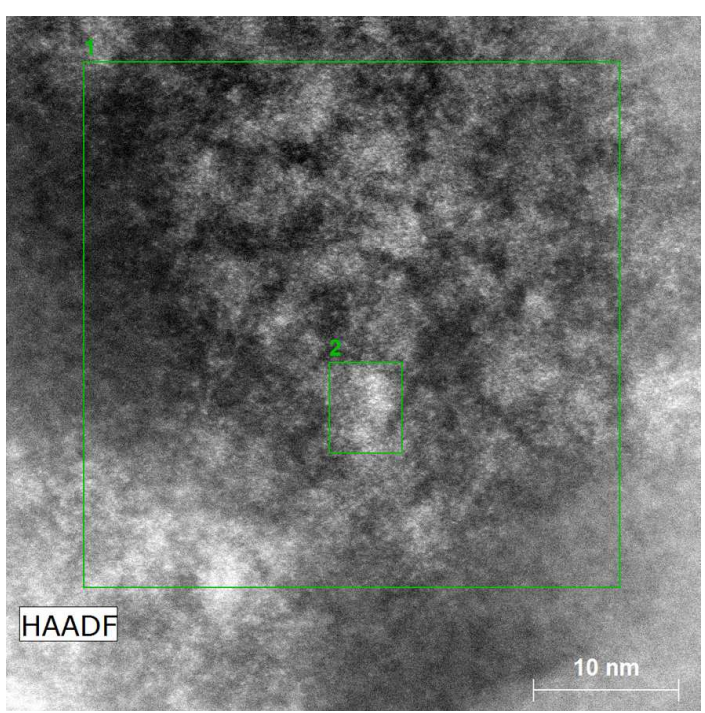

\section{Zone 1}

\begin{tabular}{|r|r|r|r|r|r|r|r|}
\hline Element & AN & series & Net & [wt.\%] & $\begin{array}{r}\text { [norm. } \\
\text { wt.\%] }\end{array}$ & $\begin{array}{r}\text { [norm. } \\
\text { at.\%] }]\end{array}$ & $\begin{array}{r}\text { Error in } \\
\text { wt.\% (1 } \\
\text { Sigma) }\end{array}$ \\
\hline Phosphoru & 15 & K-series & 486 & 22.02514 & 22.02514 & 50.71518 & 1.24897 \\
\hline Indium & 49 & L-series & 920 & 76.16285 & 76.16285 & 47.30847 & 8.29227 \\
\hline Zinc & 30 & K-series & 24 & 1.81201 & 1.81201 & 1.976344 & 0.424132 \\
\hline & & & Sum: & 100 & 100 & 100 & \\
\hline
\end{tabular}

\section{Zone 2}

\begin{tabular}{|r|r|r|r|r|r|r|r|}
\hline Element & AN & series & Net & [wt.\%] & $\begin{array}{r}\text { [norm. } \\
\text { wt.\%] }\end{array}$ & $\begin{array}{r}\text { [norm. } \\
\text { at.\%] }]\end{array}$ & $\begin{array}{r}\text { Error in } \\
\text { wt.\% (1 } \\
\text { Sigma }\end{array}$ \\
\hline Indium & 49 & L-series & 19193 & 77.61109 & 77.61109 & 50.37345 & 7.819179 \\
\hline Phosphoru & 15 & K-series & 8606 & 19.0392 & 19.0392 & 45.80895 & 0.634141 \\
\hline Zinc & 30 & K-series & 914 & 3.349702 & 3.349702 & 3.817599 & 0.180603 \\
\hline & & & Sum: & 100 & 100 & 100 & \\
\hline
\end{tabular}

Figure S2. EDX cartography with In:P:Zn stoichiometry for zone 1 and zone 2.

\section{The choice of OLA compared to other primary amines:}

We investigated the influence of the alkyl chain length of primary amines. Indeed, for CdSe QD synthesis, it has been shown that the final $\mathrm{NC}$ size could be controlled by tuning the diffusion coefficient of the solvent through control of the alkyl chain length of the carboxylic acids. ${ }^{1}$ In a similar fashion, we managed to control the size of the InP QDs by tuning the size of the carbon chain of the primary amine. As shown in Figure S3, when the carbon chain increases from 12 to 18 carbons, the NC size increases from 5 to $10 \mathrm{~nm}$ for two syntheses performed under similar conditions. Since OLA gave a good colloidal stability and is easy to handle thanks to its liquid state at room temperature, we chose it as a solvent in our studies. 


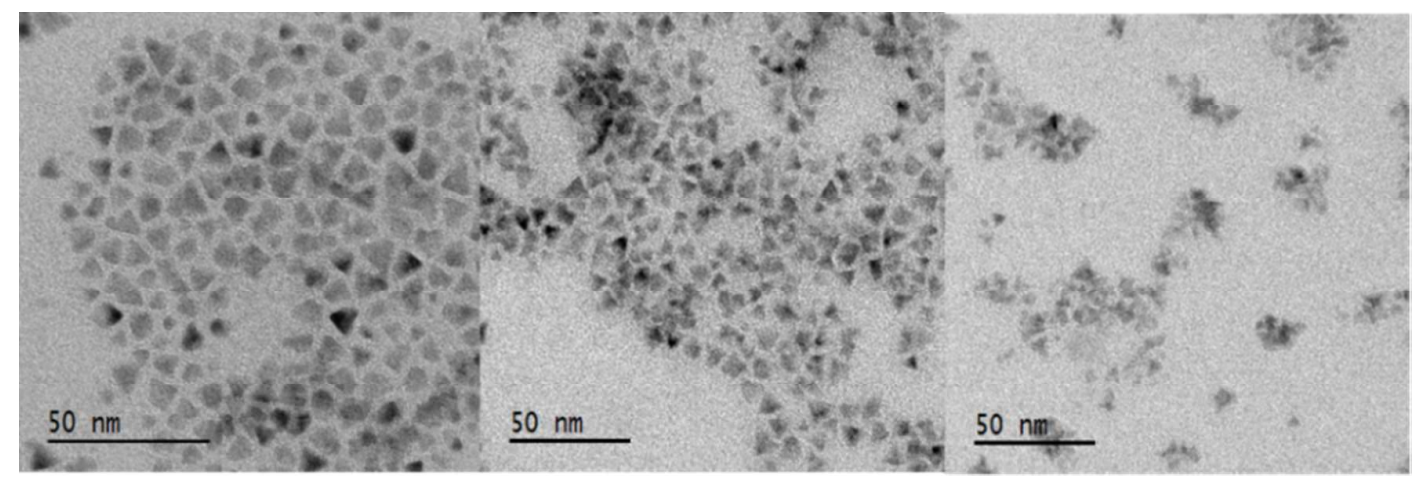

Figure S3. TEM images of InP NCs from reaction in $5 \mathrm{~mL}$ of solvent from the left to the right: Oleylamine, Hexadecylamine, Dodecylamine.

(1) De Nolf, K.; Capek, R. K.; Abe, S.; Sluydts, M.; Jang, Y.; Martins, J. C.; Cottenier, S.; Lifshitz, E.; Hens, Z. J. Am. Chem. Soc. 2015, 137, 2495-2505.

\section{Details of Chemical yield calculation}

The calculations are done based on an empiric calculation where the molar extinction coefficient depends on particle size; the yield is estimated from the estimated particles concentration. ${ }^{1}$ We take off aliquots from the mixture at different times. A precise quantity of the aliquots is weighted and put in a centrifugation tube where hexane and ethanol are added for purification. After centrifugation, the nanocrystals are dispersed in a known quantity of hexane. The absorbance of the solution is then measured. Thanks to the equation extracted from Adam et $a l$ 's work, it is possible to link the diameter of the nanocrystals $d$ and the concentration of quantum dots [QD] with $A(350 \mathrm{~nm})$ the absorbance measured at $350 \mathrm{~nm}:^{1}$

$$
[Q D]=\frac{A(350 \mathrm{~nm})}{\left(-174920.00465 d^{3}+2.4413 .106 d^{2}-9.00637 .106 d+1.05893 .107\right)} * \frac{V_{\text {cuve }}}{V_{\text {aliquots }}}
$$

The calculation is done with the diameter of the nanocrystals $d$ in $\mathrm{nm}$ and the volume $V_{\text {cuve }}$ and $V_{\text {aliquots }}$ in $\mathrm{m}^{3}$. The chemical yield $C Y$ is calculated thanks to the quantity of $\mathrm{InP} n_{I n P}$ in solution compared to the initial quantity of indium $n_{I n}$ as limitating amount. $R$ is the mean radius of InP nanocrystals, $a$ the lattice parameters and $V_{\text {total }}$ the volume of the reaction solution:

$$
\begin{gathered}
n_{\text {InP }}=\frac{A(350 \mathrm{~nm})}{\left(-174920.00465 d^{3}+2.4413 .106 d^{2}-9.00637 .106 d+1.05893 .107\right)} * \frac{V_{\text {cuve }}}{V_{\text {aliquots }}} * \frac{\frac{4}{3} \pi R^{3}}{\frac{a^{3}}{4}} * V_{\text {total }} \\
C Y=\frac{n_{\text {InP }}}{n_{\text {In }}} * 100
\end{gathered}
$$


For example, with this method, we calculate the chemical yield of a sample of $\mathrm{InP}$ with a diameter of $4.1 \mathrm{~nm}$. The absorbance at $350 \mathrm{~nm}$ is 0.645 a.u., the volume of the cuve is $3 \mathrm{~mL}$, the volume of the aliquot is $14 \mu \mathrm{L}$ and the volume of the reaction is $5 \mathrm{~mL}$. The limitating quantity of indium is $0.3 \mathrm{mmol}$. With the calculation described above, we obtain a chemical yield of $61 \%$. To confirm our method, an ICP-AES was performed by the Plateforme Analytique Inorganique of Strasbourg on InP nanoparticles and we obtained a chemical yield of $62 \%$ which is in very good agreement with our calculation.

(1) Adam, S.; Talapin, D. V.; Borchert, H.; Lobo, A.; McGinley, C.; de Castro, A. R. B.; Haase, M.; Weller, H.; Möller, T. J. Chem. Phys. 2005, 123, 084706-084710.

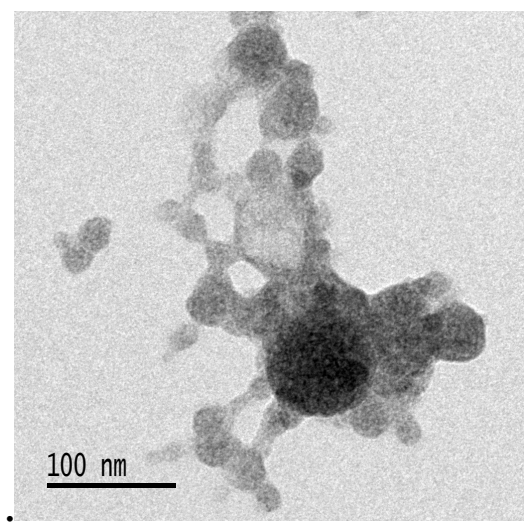

Figure S4. TEM images of InP quantum dots synthesized with 6 equivalents of oleylamine.

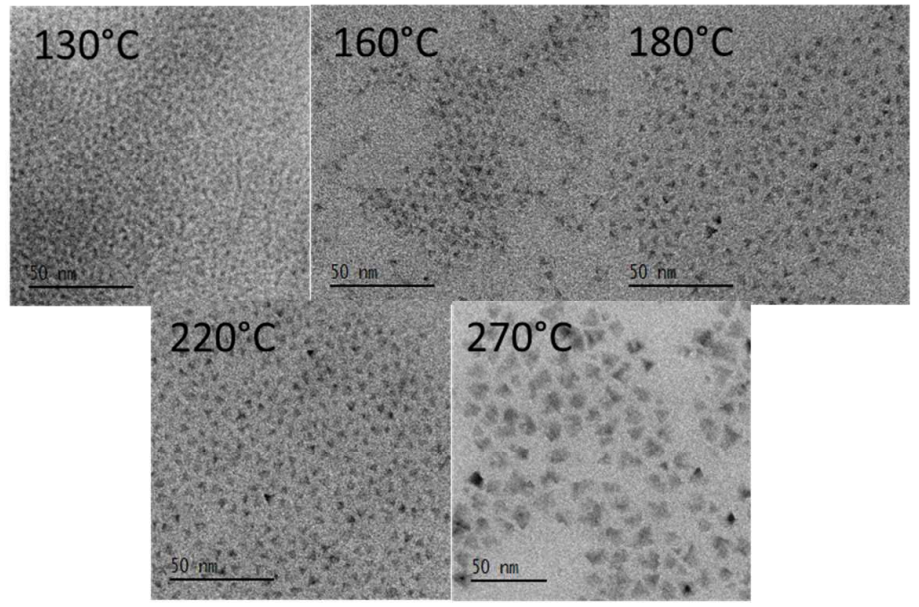

Figure S5. Evolution of the diameter and shape on TEM images of InP nanocrystals synthesized with temperature from $130^{\circ} \mathrm{C}$ to $270^{\circ} \mathrm{C}$ in a mixture of OLA (14 equiv.)/TOA(27 equiv.) with P:In 4:1. 
A

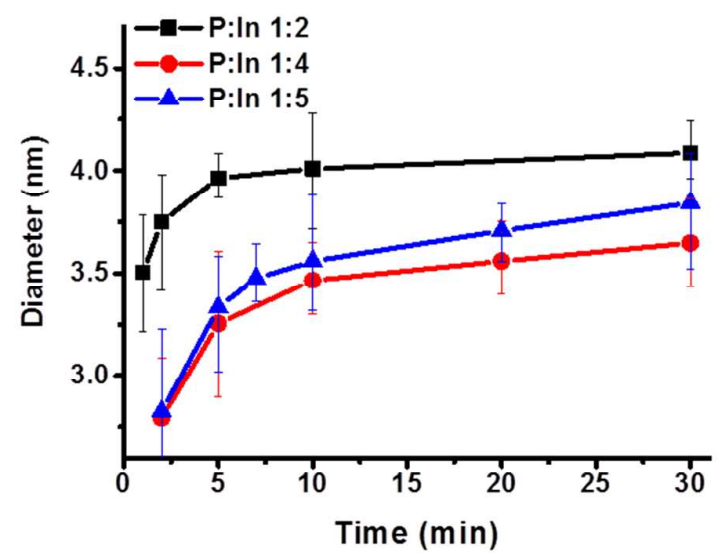

B

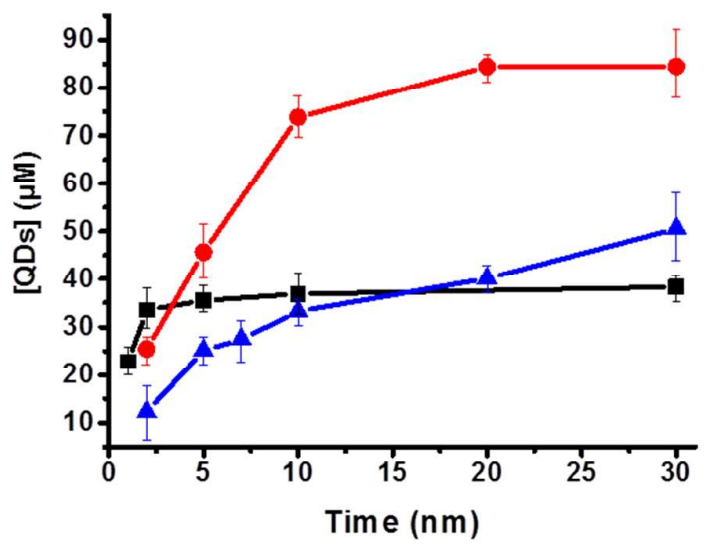

Figure S6. (A) Evolution of the nanocrystal diameter, (B) the concentration of QDs with time depending on ratio P:In at $220^{\circ} \mathrm{C}$ with 14 equivalents of OLA completed with TOA. Error bars are presented for synthesis performed multiple times.

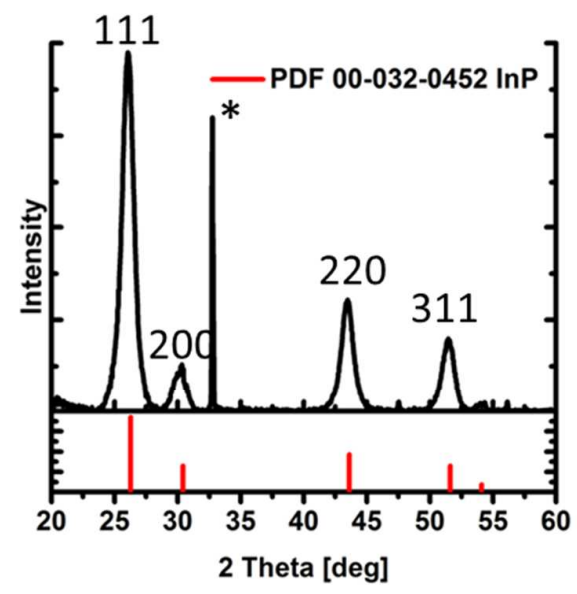

Figure S7. (A) Powder X-ray diffractogram of InP NCs. The reference peaks for bulk InP are reported at the bottom. The * peak at $33^{\circ}$ corresponds to silicon wafer.

\section{Surface oxidation after purification}

On the HAADF-STEM image (Figure S8B), the InP QDs appear with an amorphous $<\sim 1 \mathrm{~nm}$ thick layer resulting from the rapid oxidation of InP with air and undegazed solvents during the process of washing prior to TEM imaging. While oxidation of InP has been reported using various chemical analysis techniques, it is evidenced here with direct imaging techniques. ${ }^{4,5}$ This amorphous oxide layer appears as a "hairy" layer of atoms that completely cover the InP core and could block the possibility to grow core/shell NCs. The oxidation of InP QDs appears much more efficient than for their II-VI counterpart. In Figure S8 in ESI, we compared the HAADF STEM image of InP QDs and cadmium chalcogenide QDs of similar size, and exposed 
to similar oxygen sources after the synthesis. A small amorphous layer is also visible around the II-VI QDs, but it is much thinner than for the InP sample, which confirms the greater sensitivity of III-V compounds to oxidation than II-VI compounds. We would like to stress that in our case, the oxidation of the InP QDs is due to the post-synthetic treatments. If oxidation sources are avoided during the post-synthesis treatments, our QDs are not oxidized. We confirmed this claim by analyzing with ${ }^{31} \mathrm{P}$ NMR MAS spectroscopy the surface of two distinct samples of InP QDs (Figure S9). In the first case, the InP QDs were precipitated and redispersed multiple times using ethanol and hexanes under air (Figure S9A). In the second case, the precipitation was carried out under inert atmosphere and by using a 1:1 mixture of acetonitrile and acetone as polar solvent and toluene as non-polar solvent (Figure S9B). As shown on Figure S9A in ESI, the resonance corresponding to $\mathrm{InPO}_{\mathrm{x}}$ (around $0 \mathrm{ppm}$ ) is present and is significant compared to the core InP (around -200 ppm). When the InP QDs are not exposed to air, this resonance is absent. This shows that the InP QDs did not get oxidized during the synthesis but during the washing procedure with ethanol in air.

Moreover, bare InP do not show any PL during synthesis and before exposure to air (See Figure S10). It is a common fact for InP core synthesis. However, if we store the sample at air, fluorescent appear in few hours. This is certainly due to oxidation of the surface during exposition at air as it is the case for other InP NCs. Photoluminescence spectra of InP NCs after one hour under air is plotted on Figure S10. The fwhm is about $72 \mathrm{~nm}$ and the quantum yield is about $4 \%$.

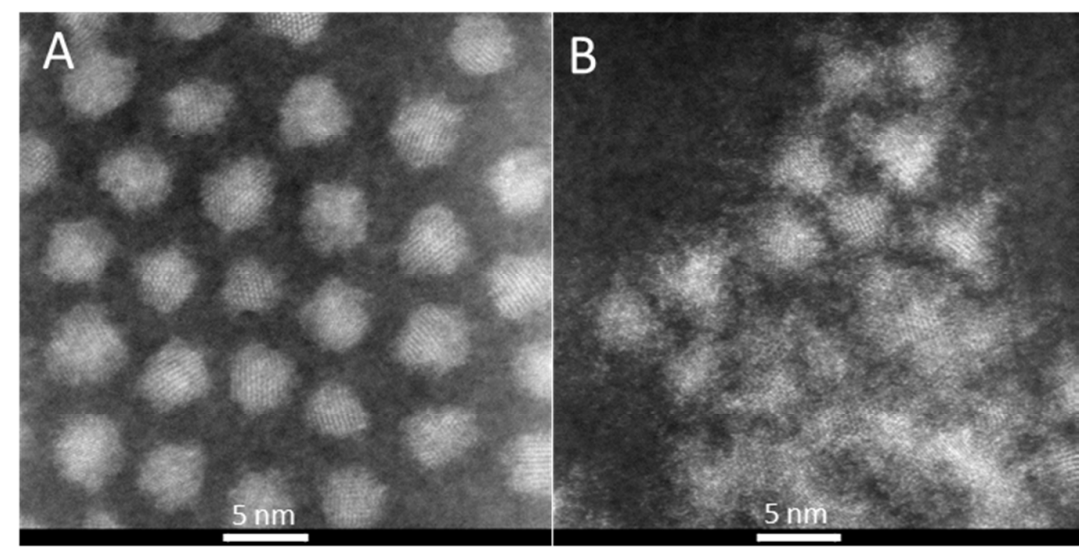

Figure S8. Atomic resolution HAADF-STEM image of (A) cadmium chalcogenide QDs and (B) indium phosphide NCs. 


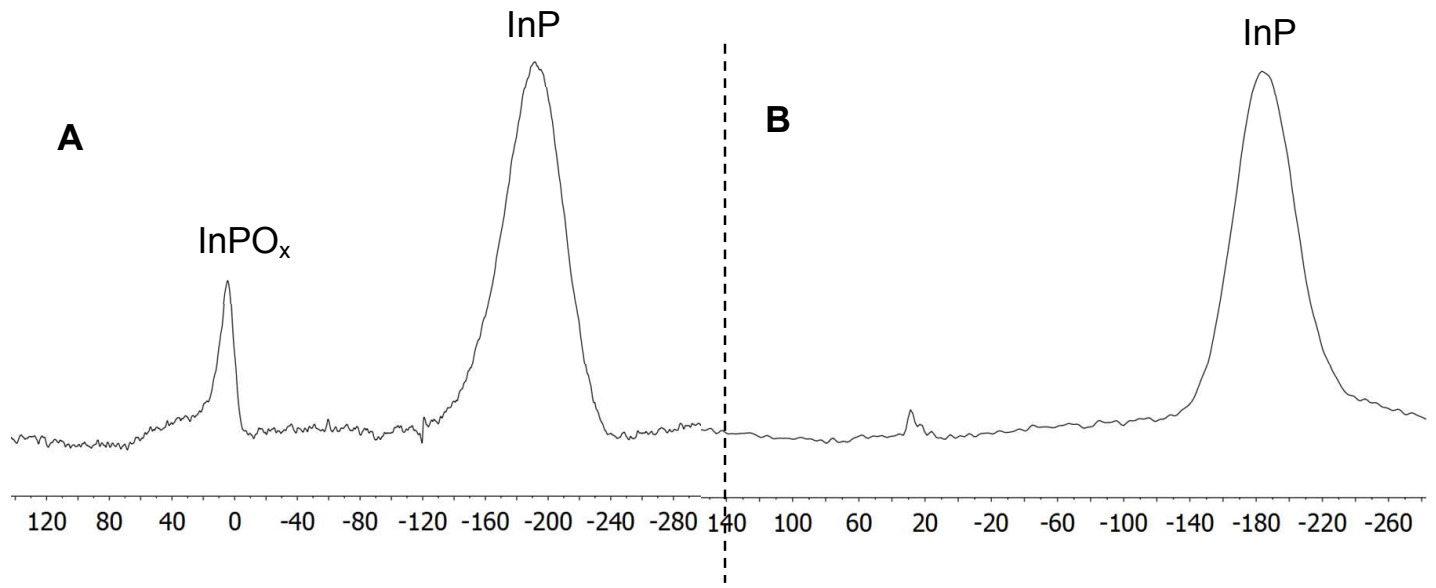

Figure S9. ${ }^{31}$ P Hahn Echo of: A) InP QDs washed with ethanol under air; B) InP QDs washed with acetone/acetonitrile under inert atmosphere. Solid state ${ }^{31} \mathrm{P}$ MAS NMR was performed at the Laboratoire de Chimie de Coordination (Toulouse) on a Bruker Avance 400WB instrument equipped with a $3.2 \mathrm{~mm}$ probe with the sample rotation frequency being set at $16 \mathrm{kHz}$.

(3) Kim, K.; Yoo, D.; Choi, H.; Tamang, S.; Ko, J.-H.; Kim, S.; Kim, Y.-H.; Jeong, S. Angew. Chemie Int. Ed. 2016, 55, 3714-3718.

(4) Virieux, H.; Le Troedec, M.; Cros-Gagneux, A.; Ojo, W.-S.; Delpech, F.; Nayral, C.; Martinez, H.; Chaudret, B. J. Am. Chem. Soc. 2012, 134, 19701-19708.

(5) Hoflund, G. B.; Corallo, C. F. Surf. Interface Anal. 1986, 9, 319-323.

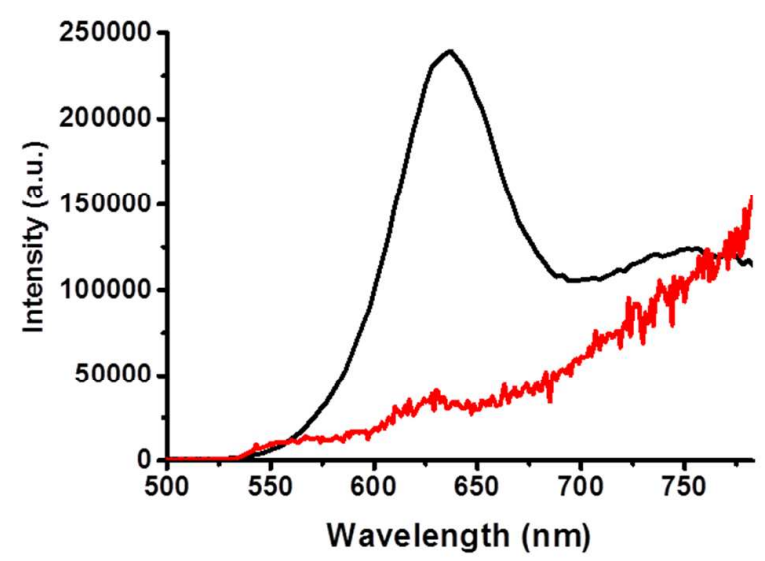

Figure S10. Photoluminescence spectra of bare InP NCs synthesized at $220^{\circ} \mathrm{C}$ after storage under air for one hour (black) compared to as-synthesized InP NCs without exposure to air (red). 


\section{Mechanism details}

All reactions were routinely performed under an inert atmosphere of argon or nitrogen using standard Schlenk and glovebox techniques and dry deoxygenated solvents. Solvents were obtained from an MBraun Solvent Purifying system SPS 800. Nuclear magnetic resonance spectra were recorded on a Bruker AC-300 SY spectrometer operating at $121.5 \mathrm{MHz}$ for ${ }^{31} \mathrm{P} .{ }^{31} \mathrm{P}$ chemical shifts are relative to an $85 \% \mathrm{H}_{3} \mathrm{PO}_{4}$ external reference. Coupling constants are given in Hertz. The following abbreviations are used: s, singlet; d, doublet; m, multiplet. MALDI-TOF mass spectrometry was performed on a Waters MALDI Micro MX

Characterization of transaminated products:

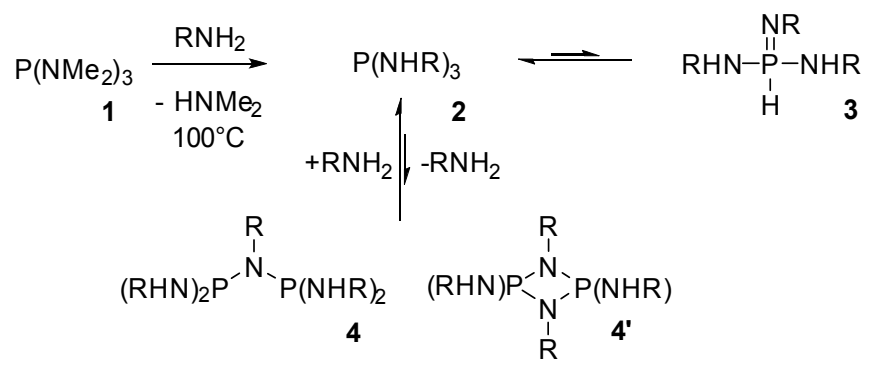

Scheme S1: reminder of substitution reactions of $P\left(\mathrm{NMe}_{2}\right)_{3}$ with a primary amine

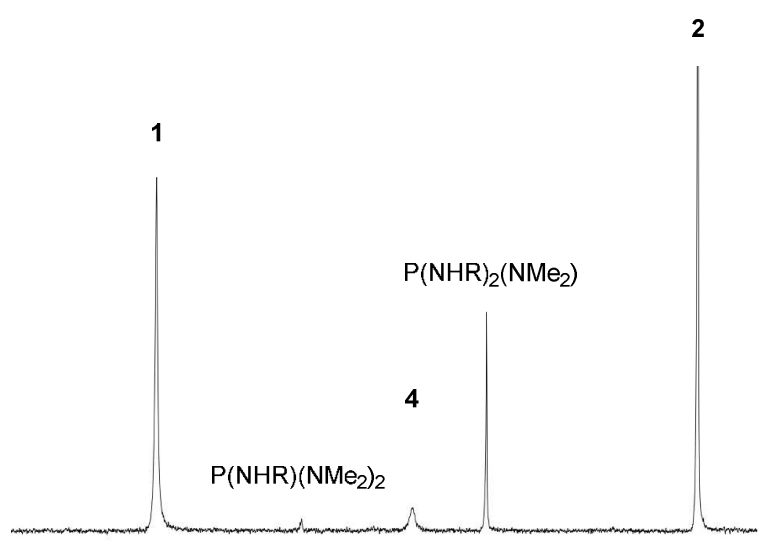

$12812612412212011811611411211010810610410210098 \quad 96$

Figure S11: ${ }^{31} \mathrm{P}$ NMR spectrum of $\mathrm{P}\left(\mathrm{NMe}_{2}\right)_{3}$ reacted for 12 hours at $50{ }^{\circ} \mathrm{C}$ with 35 equivalents of oleylamine. 
Preparation of MALDI-TOF samples: $10 \mu \mathrm{L}$ of reaction solution was diluted in $1 \mathrm{~mL}$ of THF. 1 or $2 \mathrm{mg}$ of pyrene matrix (purified by sublimation) was added. A $1 \mu \mathrm{L}$ drop of the solution was deposited on the MALDI grid.

To characterize products $\mathbf{2}, \mathbf{3}, \mathbf{4}, \mathbf{4}$, experiments were carried out using hexadecylamine instead of OLA. Indeed, in the case of OLA, we observed that 2, 3', 4, 4' underwent fragmentation and/or multiple ionization during the MALDI-TOF experiment, thus making their identification impossible, while in the case of hexadecylamine, the expected $\mathrm{m} / \mathrm{z}$ could be obtained.

Formation of products 2, 4 and 4' using hexadecylamine: $450 \mathrm{mg}$ of hexadecylamine (1.9 mmol) was weighted in a Schlenk. $58.2 \mu \mathrm{L}$ of $\mathrm{P}\left(\mathrm{NMe}_{2}\right)_{3}(0.32 \mathrm{mmol})$ were added inside the glovebox. The mixture was heated to $100^{\circ} \mathrm{C}$ for 5 hours. Then heating was stopped and the mixture left to cool down to room temperature. The solid was dissolved in $5 \mathrm{~mL}$ of THF and aliquots were taken for NMR and MALDI-TOF analysis, showing the presence of products 2, 3, 4, and 4'. ${ }^{31} \mathrm{P}$ NMR (THF): 2: 98 ppm (s); 4: 111 ppm (s) 4': 183 ppm (s).

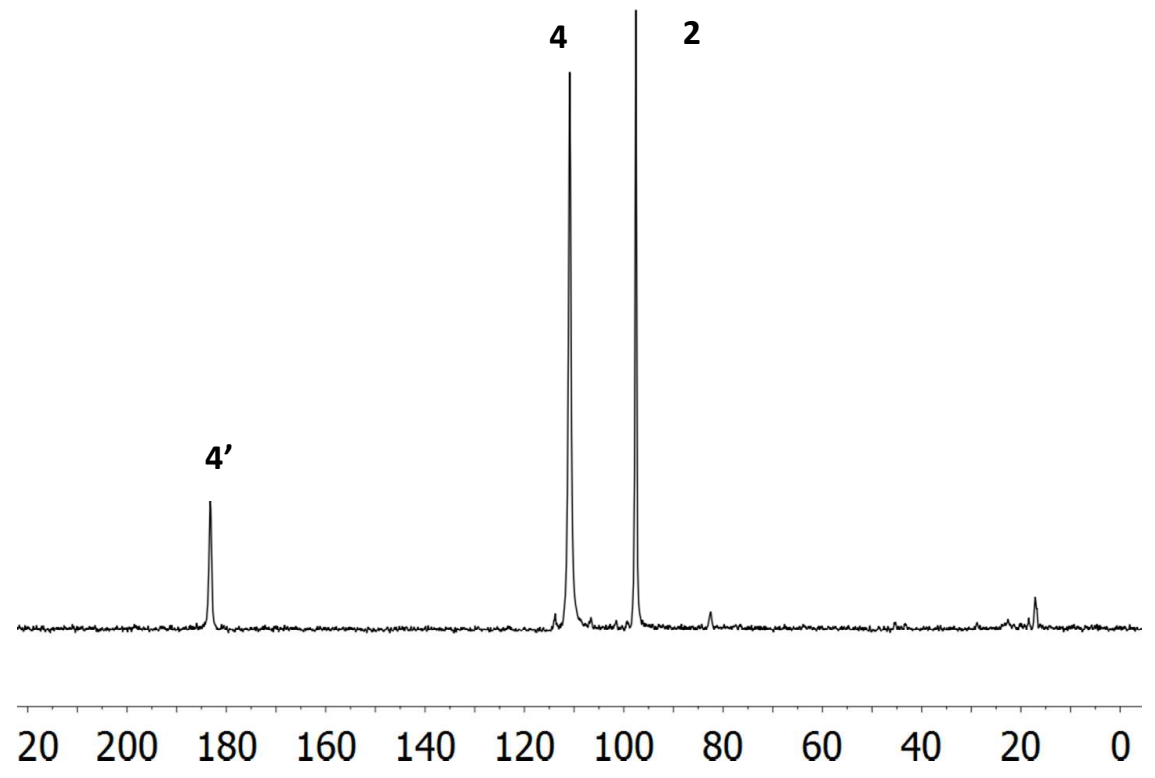

Figure S12: ${ }^{31} \mathrm{P}$ NMR spectrum of the mixture of 2, 4, 4' in the case of hexadecylamine in THF. 


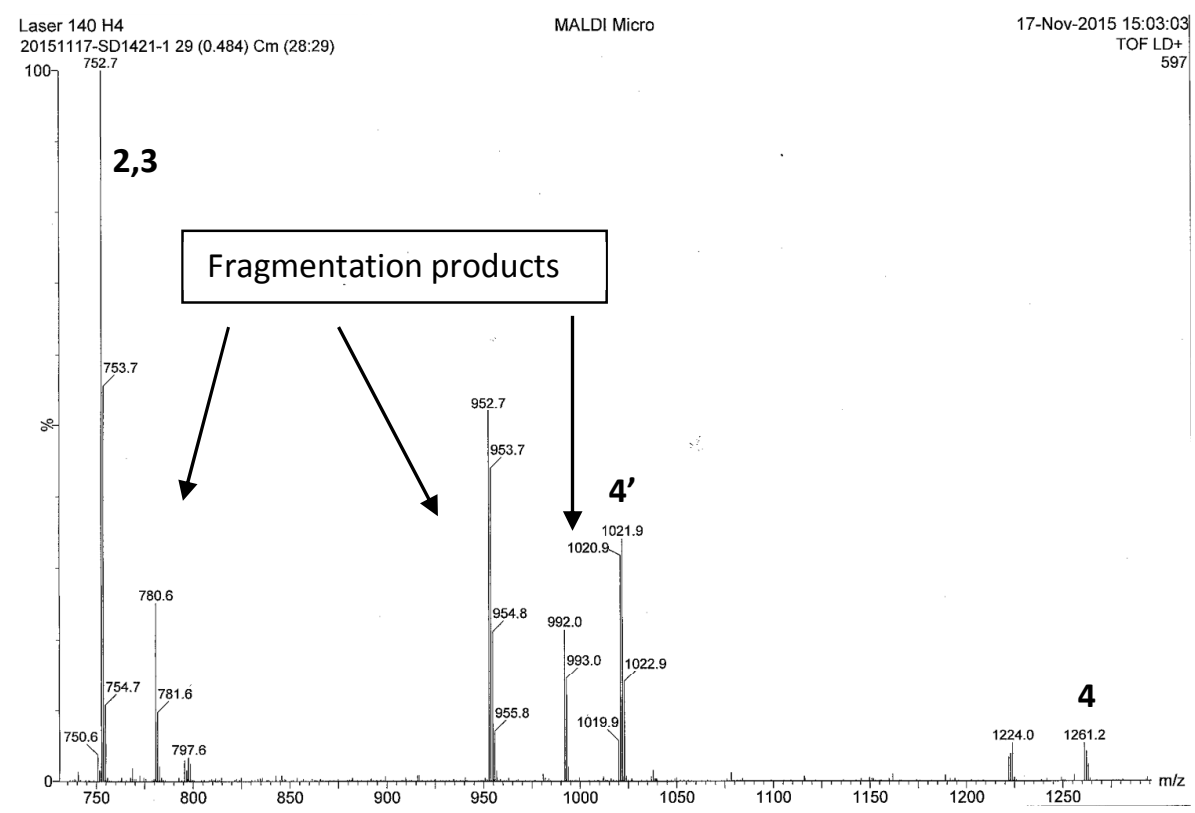

Figure S13: MALDI-TOF mass spectrum of the mixture of $2,3,4,4$ ' in the case of hexadecylamine Expected m/z: 2: $752 \mathrm{~g} / \mathrm{mol} ; 4: 1263 \mathrm{~g} / \mathrm{mol} ; 4^{\prime}: 1022 \mathrm{~g} / \mathrm{mol}$

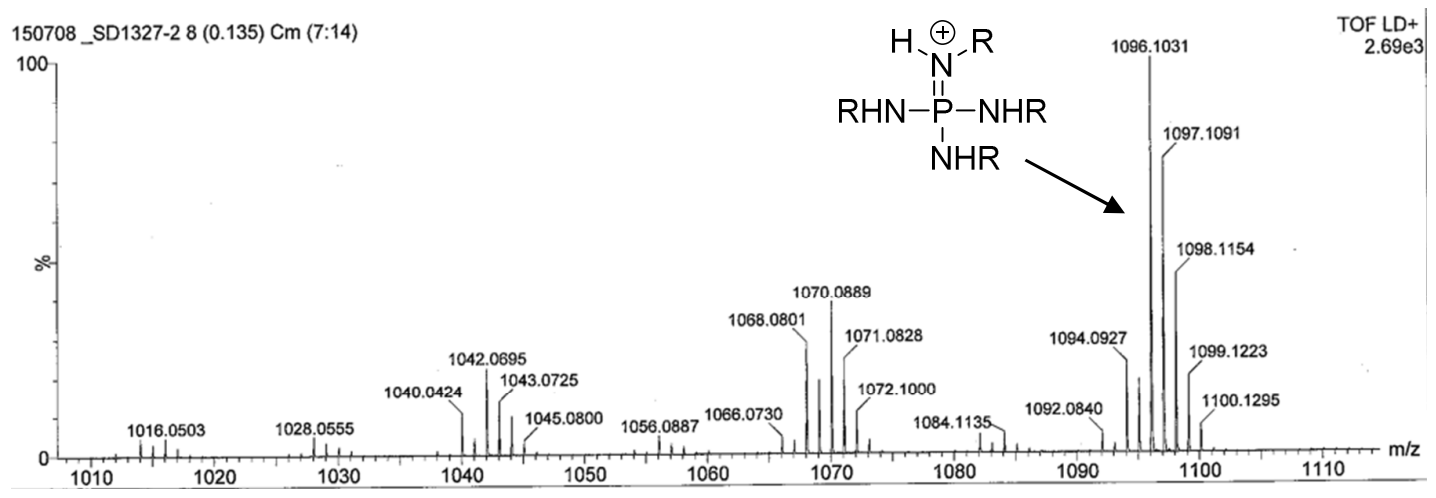

Figure S14: MALDI-TOF mass spectrum of 5 in the case of oleylamine<smiles>[R]NP(N[R])(N[R])(N[R])N[R]</smiles> 


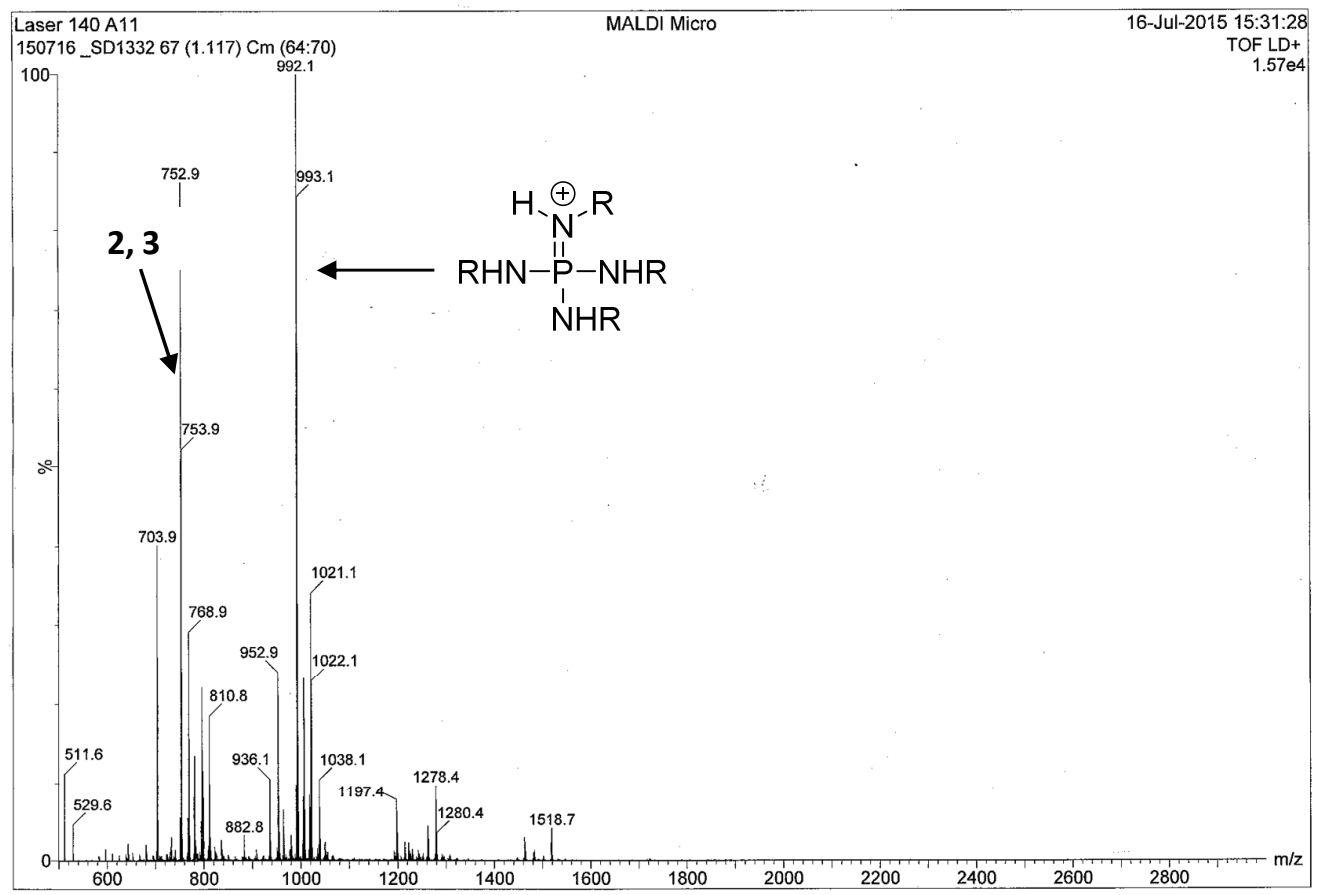

Figure S15: MALDI-TOF mass spectrum of 2, 3 and 5 in the case of HDA

Expected $\mathrm{m} / \mathrm{z}$ in the case of HDA:
○ 2, 3: $752 \mathrm{~g} / \mathrm{mol}$
○ $\mathrm{P}(\mathrm{NHR})_{4}{ }^{+}$fragment: $993 \mathrm{~g} / \mathrm{mol}$

Reaction of $\mathrm{InCl}_{3}$ and $\mathrm{P}\left(\mathrm{NMe}_{2}\right)_{3}$ in trioctylamine, without oleylamine: $15 \mathrm{mg}$ of $\mathrm{InCl}_{3}(68 \mu \mathrm{mol})$ is suspended in $1 \mathrm{~mL}$ of dried, degassed trioctylamine $(2.3 \mathrm{mmol})$ and heated to $150{ }^{\circ} \mathrm{C}$ in a Schlenk for 2 hours. After cooling down to room temperature, $49 \mu \mathrm{L}$ of $\mathrm{P}\left(\mathrm{NMe}_{2}\right)_{3}(270 \mu \mathrm{mol})$ are added inside the glovebox. A $0.5 \mathrm{~mL}$ aliquot is taken in a J-Young tube and heated outside the glovebox for 2 hours. No formation of InP QDs is observed.

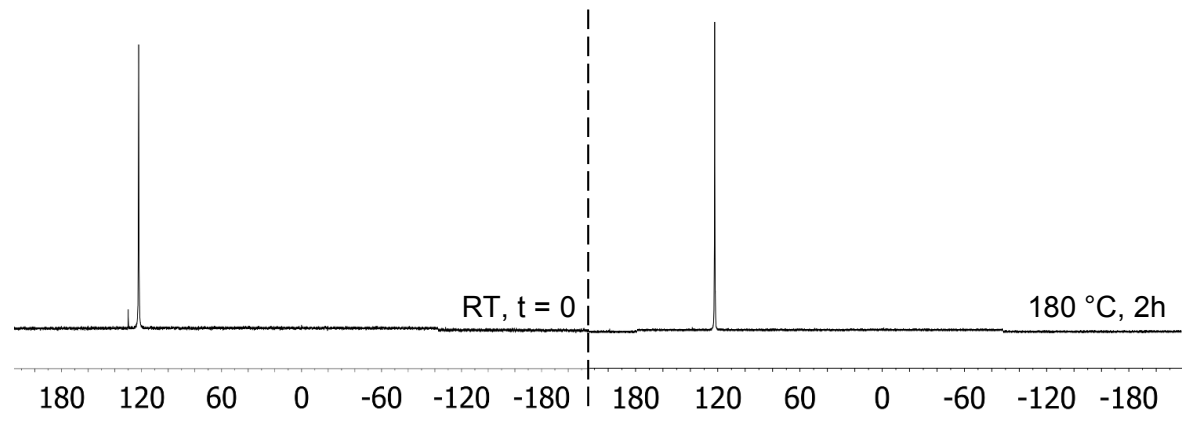

Figure S16: ${ }^{31} \mathrm{P}$ NMR of the mixture of $\mathrm{InCl}_{3}$, TOA and $\mathrm{P}\left(\mathrm{NMe}_{2}\right)_{3}$ before and after heating at $180{ }^{\circ} \mathrm{C}, 2 \mathrm{~h}$ 
Control experiments with $\mathrm{ZnCl}_{2}$

The reaction was followed using three different conditions:

a) With $\mathrm{InCl}_{3}, \mathrm{P}\left(\mathrm{NMe}_{2}\right)_{3}$, OLA (ratio 1:4:35)

b) With $\mathrm{ZnCl}_{2}, \mathrm{P}\left(\mathrm{NMe}_{2}\right)_{3}$, OLA (ratio 1:4:35)

c) With $\mathrm{InCl}_{3}, \mathrm{ZnCl}_{2}, \mathrm{P}\left(\mathrm{NMe}_{2}\right)_{3}$, OLA (ratio 1:1:4:35)

The indium and/or zinc salts were dissolved in OLA. Then $\mathrm{P}\left(\mathrm{NMe}_{2}\right)_{3}$ was added inside a glovebox. The mixtures were transferred into J-Young NMR tubes. These tubes were taken outside the glovebox, put under active vacuum on the Schlenk line and heated to $85{ }^{\circ} \mathrm{C}$ for 24 hours to perform the transamination reaction. The active vacuum is necessary otherwise the system is closed and the transamination is very slow. The absence of stirring slows down the reaction compared to the optimized reaction in a standard reaction vessel. Mixtures a and $\mathbf{c}$ turned light yellow, corresponding to the formation of a low amount of InP QDs, which is corroborated by the presence of a low amount of product $\mathbf{5}$ in the ${ }^{31} \mathrm{P}\left\{{ }^{1} \mathrm{H}\right\}$ NMR spectra; mixture $\mathbf{b}$ remained colorless, and in this case no product 5 is observed by ${ }^{31} \mathrm{P}\left\{{ }^{1} \mathrm{H}\right\}$ NMR.

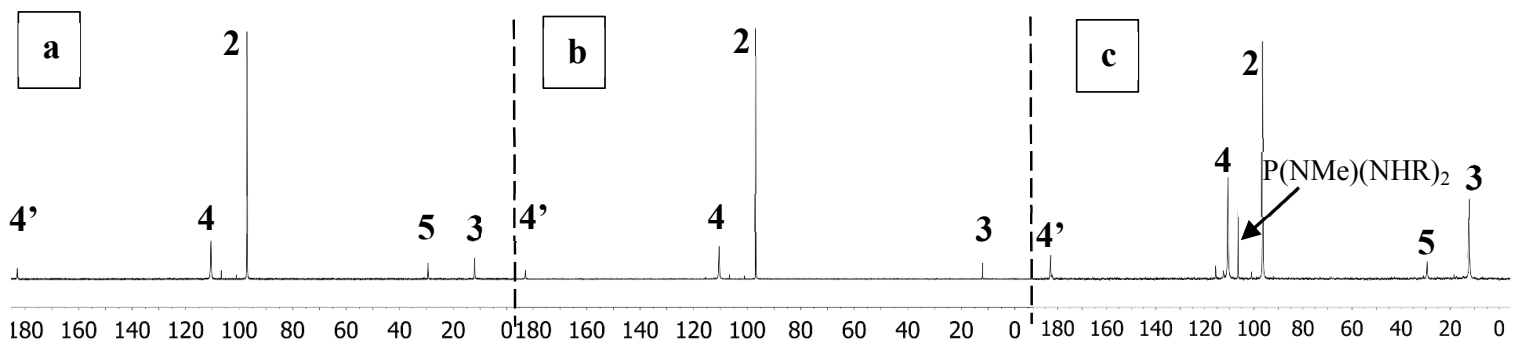

Figure S17: ${ }^{31} \mathrm{P}\left\{{ }^{1} \mathrm{H}\right\}$ NMR spectra illustrating the transamination reaction after 24 hours at $85{ }^{\circ} \mathrm{C}$ under active vacuum in the presence of a) $\mathrm{InCl}_{3}$, b) $\mathrm{ZnCl}_{2}$, c) $\mathrm{InCl}_{3}$ and $\mathrm{ZnCl}_{2}$

Then, the temperature of the oil bath was set to $180{ }^{\circ} \mathrm{C}$ and the mixtures left to react for one hour. Again, the absence of stirring slowed down the reaction. Mixtures a and $\mathbf{c}$ turned dark red because of the formation of $\mathrm{InP}$ QDs and the amount of product 5 increased. Mixture b remained colorless. In the absence of $\mathrm{InCl}_{3}$ (mixture b) no formation of $\mathbf{5}$ is observed

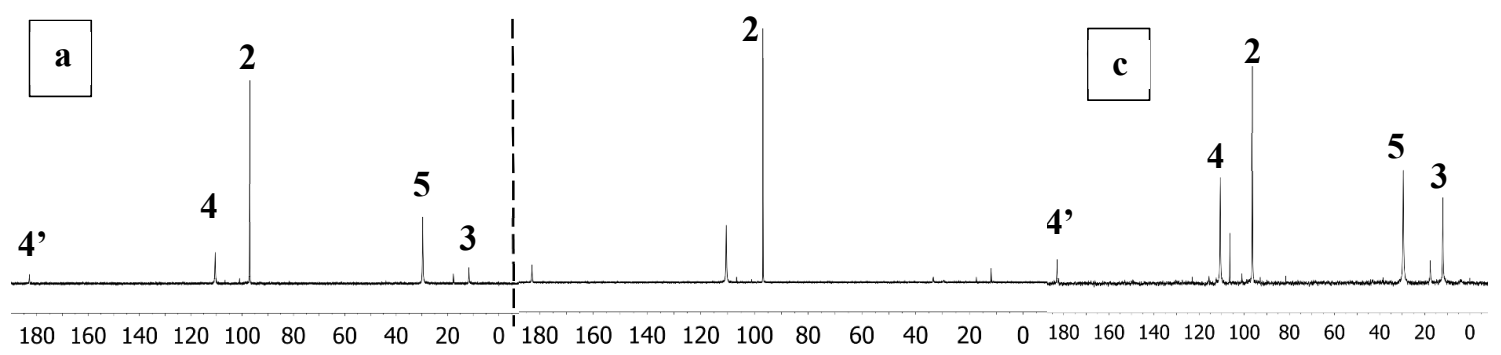

Figure S18: ${ }^{31} \mathrm{P}\left\{{ }^{1} \mathrm{H}\right\}$ NMR spectra after one hour at $180{ }^{\circ} \mathrm{C}$ in the presence of a) $\mathrm{InCl}_{3}$, b) $\left.\mathrm{ZnCl}_{2}, \mathrm{c}\right) \mathrm{InCl}_{3}$ and $\mathrm{ZnCl}_{2}$

In conclusion, the presence of $\mathrm{ZnCl}_{2}$ does not lead to any reaction other than the transamination. When both $\mathrm{InCl}_{3}$ and $\mathrm{ZnCl}_{2}$ are present, the equilibria between the P-containing are different. Indeed, in this case, the total concentration of metal salts which are coordinated by OLA is higher, favoring bridging products like 4 . 


\section{Computational Details}

Calculations were performed with the Gaussian09 suite of software, ${ }^{1}$ using the B3PW91 functional, ${ }^{2,3}$ the 6$31 \mathrm{G}^{*}$ basis set for all non metal atoms, ${ }^{4}$ and LANL2DZ ECP basis set for $\mathrm{In}^{5}$ All geometries have been computed and optimized in the gas phase. The stationary points were characterized as minima by full vibration frequencies calculations (no imaginary frequency). A NBO analysis was carried out at the same level of theory on the optimized structures.

Cartesian coordinates, three lower frequencies and thermochemistry of $\mathrm{CH}_{3} \mathrm{NH}_{2}$

\begin{tabular}{|c|c|c|c|c|c|}
\hline Center & Atomic & Atomic & \multicolumn{3}{|c|}{ Coordinates (Angstroms) } \\
\hline Number & Number & Type & $\mathrm{X}$ & Y & Z \\
\hline 1 & 7 & 0 & 0.748861 & -0.000015 & -0.124775 \\
\hline 2 & 1 & 0 & 1.141480 & -0.812393 & 0.344351 \\
\hline 3 & 6 & 0 & -0.702135 & -0.000007 & 0.017690 \\
\hline 4 & 1 & 0 & -1.085165 & -0.001165 & 1.054135 \\
\hline 5 & 1 & 0 & -1.113311 & 0.881525 & -0.486746 \\
\hline 6 & 1 & 0 & -1.113691 & -0.880178 & -0.488850 \\
\hline 7 & 1 & 0 & 1.141469 & 0.812359 & 0.344390 \\
\hline
\end{tabular}

\begin{tabular}{lrrr} 
& \multicolumn{1}{c}{1} & \multicolumn{1}{c}{2} & \multicolumn{1}{c}{3} \\
& \multicolumn{1}{c}{ A } & \multicolumn{1}{c}{ A } & \multicolumn{1}{c}{ A } \\
Frequencies -- & 332.1754 & 874.1222 & 987.8976 \\
Red. masses -- & 1.0308 & 1.2221 & 1.0530 \\
Frc consts -- & 0.0670 & 0.5502 & 0.6055 \\
IR Inten -- & 47.0890 & 179.0774 & 0.0579
\end{tabular}

Sum of electronic and zero-point Energies=

Sum of electronic and thermal Energies=

Sum of electronic and thermal Enthalpies=

$-95.747869$

Sum of electronic and thermal Free Energies=

$-95.775078$ 
Cartesian coordinates, three lower frequencies and thermochemistry of $\mathrm{P}\left(\mathrm{NHCH}_{3}\right)_{3}$

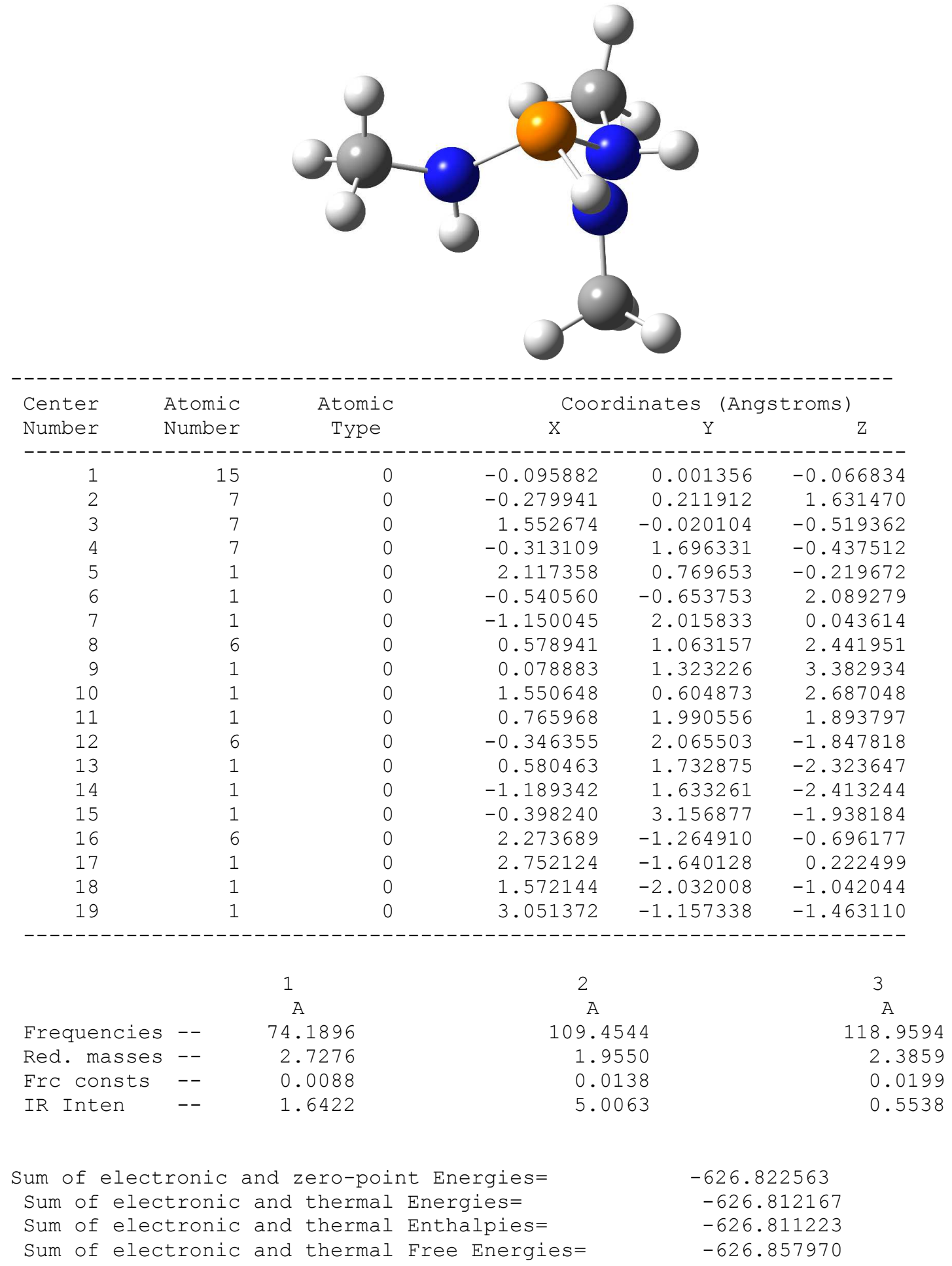


Cartesian coordinates, three lower frequencies and thermochemistry of $\operatorname{InCl}_{3}\left(\mathrm{NH}_{2} \mathrm{CH}_{3}\right)_{2}$

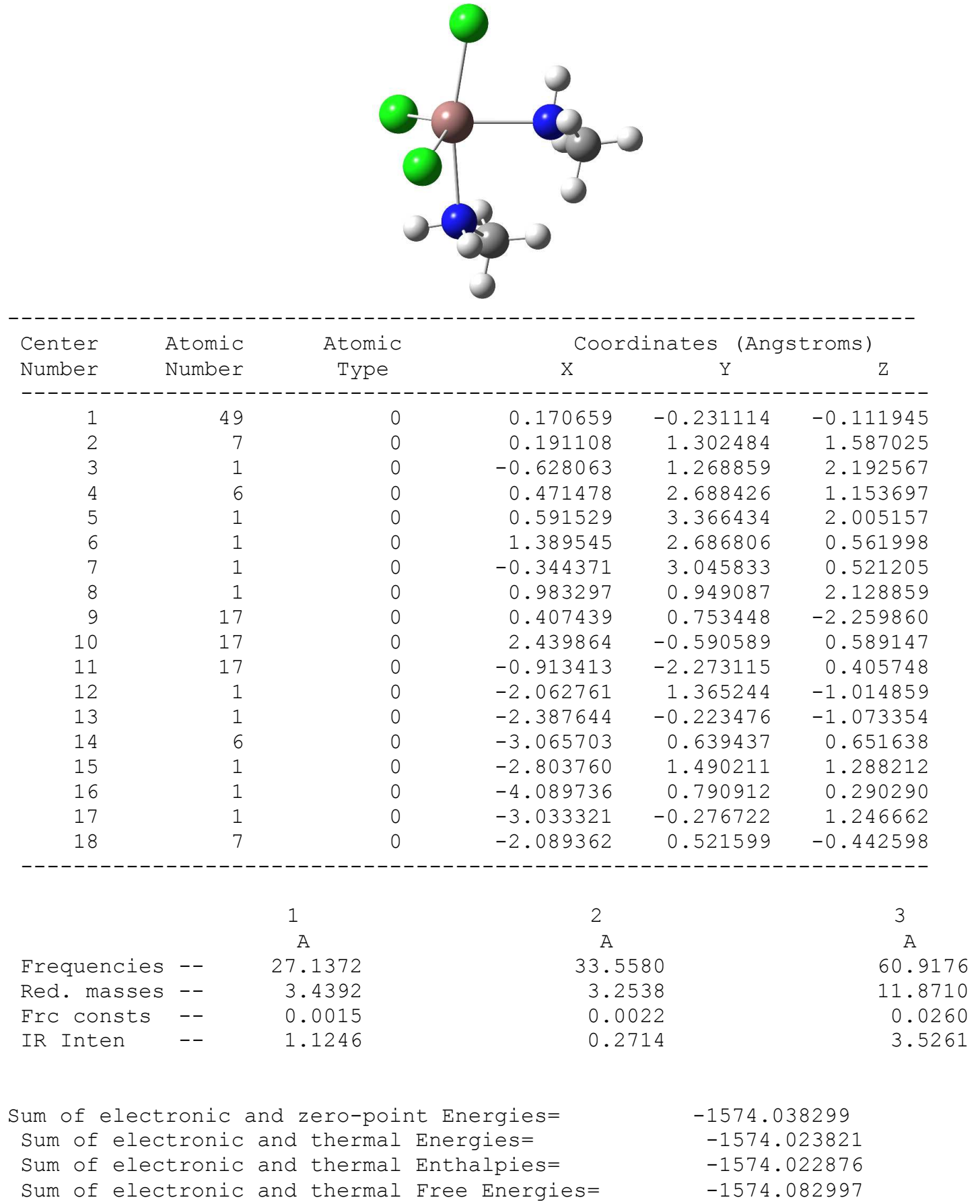


Cartesian coordinates, three lower frequencies and thermochemistry of $\mathrm{InCl}_{3}\left(\mathrm{NH}_{2} \mathrm{CH}_{3}\right)_{3}$

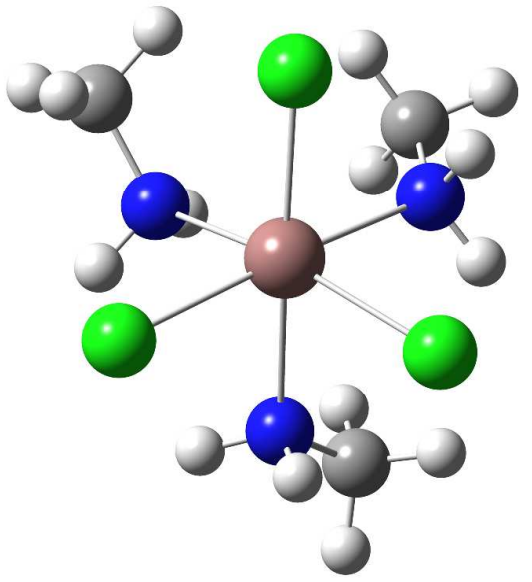

\begin{tabular}{|c|c|c|c|c|c|}
\hline \multirow{2}{*}{$\begin{array}{l}\text { Center } \\
\text { Number }\end{array}$} & \multirow{2}{*}{$\begin{array}{l}\text { Atomic } \\
\text { Number }\end{array}$} & \multirow{2}{*}{$\begin{array}{c}\text { Atomic } \\
\text { Type }\end{array}$} & \multicolumn{3}{|c|}{ Coordinates (Angstroms) } \\
\hline & & & $\mathrm{x}$ & Y & Z \\
\hline 1 & 49 & 0 & 0.352014 & 0.161382 & -0.165500 \\
\hline 2 & 7 & 0 & 0.180220 & -0.024875 & 2.190269 \\
\hline 3 & 1 & 0 & 1.184495 & 0.073602 & 2.351275 \\
\hline 4 & 6 & 0 & -0.307734 & -1.219901 & 2.891266 \\
\hline 5 & 1 & 0 & -0.120166 & -1.183870 & 3.971179 \\
\hline 6 & 1 & 0 & -1.385617 & -1.326995 & 2.735365 \\
\hline 7 & 1 & 0 & 0.202480 & -2.093117 & 2.477724 \\
\hline 8 & 1 & 0 & -0.236497 & 0.825526 & 2.565491 \\
\hline 9 & 17 & 0 & 2.291179 & -1.242758 & 0.156579 \\
\hline 10 & 17 & 0 & -0.012838 & 0.275105 & -2.577349 \\
\hline 11 & 7 & 0 & -1.748613 & 1.344929 & -0.207285 \\
\hline 12 & 6 & 0 & -2.526272 & 1.726342 & 0.979103 \\
\hline 13 & 1 & 0 & -3.387730 & 2.361169 & 0.738155 \\
\hline 14 & 1 & 0 & -2.889978 & 0.830446 & 1.492113 \\
\hline 15 & 1 & 0 & -1.871217 & 2.282795 & 1.654358 \\
\hline 16 & 1 & 0 & -1.770347 & -1.818976 & 0.350497 \\
\hline 17 & 1 & 0 & -1.566299 & -1.428080 & -1.231995 \\
\hline 18 & 6 & 0 & -0.433297 & -3.024894 & -0.656035 \\
\hline 19 & 1 & 0 & 0.154761 & -3.329446 & 0.210511 \\
\hline 20 & 1 & 0 & -1.172982 & -3.798197 & -0.895260 \\
\hline 21 & 1 & 0 & 0.253483 & -2.903380 & -1.495127 \\
\hline 22 & 7 & 0 & -1.074078 & -1.720009 & -0.386556 \\
\hline 23 & 1 & 0 & -2.347575 & 0.954938 & -0.933874 \\
\hline 24 & 1 & 0 & -1.339670 & 2.184598 & -0.622060 \\
\hline 25 & 17 & 0 & 1.136617 & 2.390907 & 0.460675 \\
\hline
\end{tabular}

1

A

Frequencies --

Red. masses --

12.8272

Frc consts --

IR Inten

$--$
2.2023

0.0002

0.2650

\section{2}

A

32.9756

2.5368

0.0016

1.6612
3

A

45.7484

2.5206

0.0031

0.6899

Sum of electronic and zero-point Energies= Sum of electronic and thermal Energies=

$-1669.812222$ 
Sum of electronic and thermal Enthalpies=

$-1669.792705$

Sum of electronic and thermal Free Energies=

$-1669.862129$

Cartesian coordinates, three lower frequencies and thermochemistry of $\operatorname{InCl}_{3}\left(\mathrm{NH}_{2} \mathrm{CH}_{3}\right)_{4}$

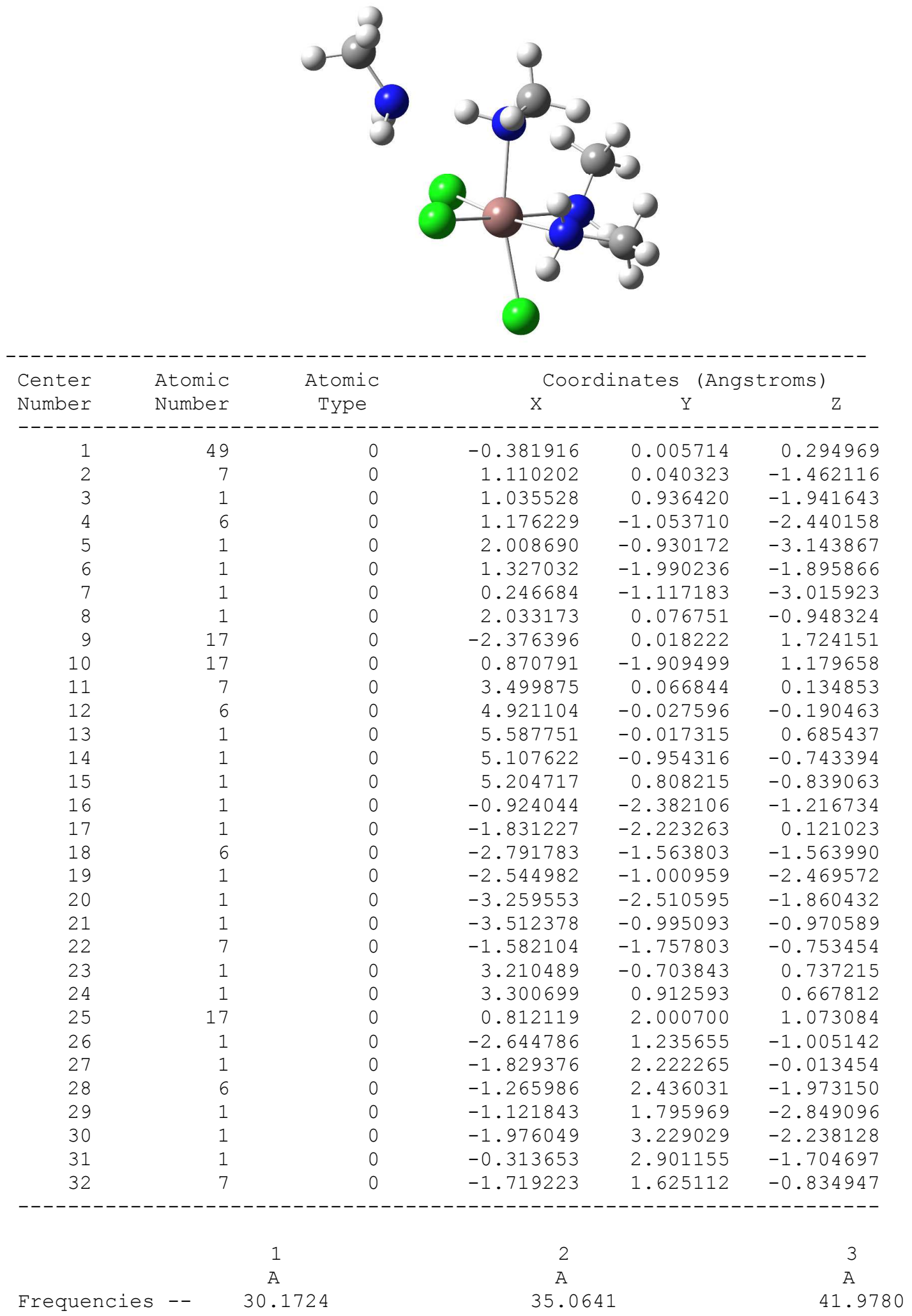




\begin{tabular}{|c|c|c|c|}
\hline Red. masses & -- & 2.8488 & 2.6997 \\
\hline Erc consts & -- & 0.0015 & 0.0020 \\
\hline IR Inten & -- & 0.0084 & 0.6617 \\
\hline
\end{tabular}

Sum of electronic and zero-point Energies= Sum of electronic and thermal Energies= Sum of electronic and thermal Enthalpies= $-1765.584761$

$-1765.561924$

$-1765.560980$

Sum of electronic and thermal Free Energies=

$-1765.639595$

Cartesian coordinates, three lower frequencies and thermochemistry of $\operatorname{InCl}_{3}\left(\mathrm{NH}_{2} \mathrm{CH}_{3}\right)_{2}\left(\mathrm{P}\left(\mathrm{NHCH}_{3}\right)_{3}\right) \mathbf{A}_{\mathbf{I}}$

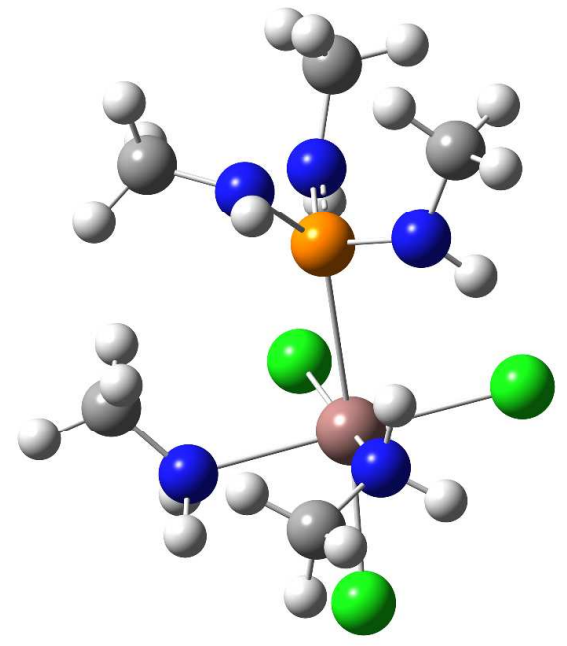

\begin{tabular}{|c|c|c|c|c|c|}
\hline \multirow{2}{*}{$\begin{array}{l}\text { Center } \\
\text { Number }\end{array}$} & \multirow{2}{*}{$\begin{array}{l}\text { Atomic } \\
\text { Number }\end{array}$} & \multirow{2}{*}{$\begin{array}{l}\text { Atomic } \\
\text { Type }\end{array}$} & \multicolumn{3}{|c|}{ Coordinates (Angstroms) } \\
\hline & & & $\mathrm{X}$ & Y & Z \\
\hline 1 & 49 & 0 & -1.099683 & -0.081536 & -0.275694 \\
\hline 2 & 7 & 0 & -1.450255 & 2.058784 & 0.626743 \\
\hline 3 & 1 & 0 & -1.974087 & 2.425486 & -0.169790 \\
\hline 4 & 6 & 0 & -0.366761 & 2.984264 & 0.976414 \\
\hline 5 & 1 & 0 & -0.734758 & 3.981652 & 1.246372 \\
\hline 6 & 1 & 0 & 0.200082 & 2.576494 & 1.817118 \\
\hline 7 & 1 & 0 & 0.300903 & 3.073059 & 0.116126 \\
\hline 8 & 1 & 0 & -2.131333 & 1.968351 & 1.379135 \\
\hline 9 & 17 & 0 & -0.668784 & 1.160788 & -2.339503 \\
\hline 10 & 17 & 0 & -0.686595 & -2.401258 & -0.989811 \\
\hline 11 & 7 & 0 & -1.037200 & -1.072734 & 1.862646 \\
\hline 12 & 6 & 0 & -1.583546 & -0.404427 & 3.051007 \\
\hline 13 & 1 & 0 & -1.586495 & -1.053293 & 3.935332 \\
\hline 14 & 1 & 0 & -0.985742 & 0.483796 & 3.277512 \\
\hline 15 & 1 & 0 & -2.610703 & -0.100657 & 2.833002 \\
\hline 16 & 1 & 0 & -0.079871 & -1.396621 & 2.021496 \\
\hline 17 & 1 & 0 & -1.587477 & -1.905067 & 1.645097 \\
\hline 18 & 17 & 0 & -3.525259 & -0.120844 & -0.015530 \\
\hline 19 & 1 & 0 & 1.731925 & 0.507823 & -2.024182 \\
\hline 20 & 15 & 0 & 1.728544 & -0.037154 & 0.171683 \\
\hline 21 & 1 & 0 & 1.282405 & -2.235576 & 0.301357 \\
\hline 22 & 1 & 0 & 2.733606 & 0.368850 & 2.207434 \\
\hline 23 & 6 & 0 & 3.278523 & -2.266205 & 0.878801 \\
\hline 24 & 1 & 0 & 3.649283 & -2.664768 & -0.074804 \\
\hline 25 & 1 & 0 & 4.004000 & -1.543060 & 1.258466 \\
\hline 26 & 1 & 0 & 3.212525 & -3.094038 & 1.593613 \\
\hline 27 & 6 & 0 & 3.202194 & 2.111606 & 1.165765 \\
\hline
\end{tabular}




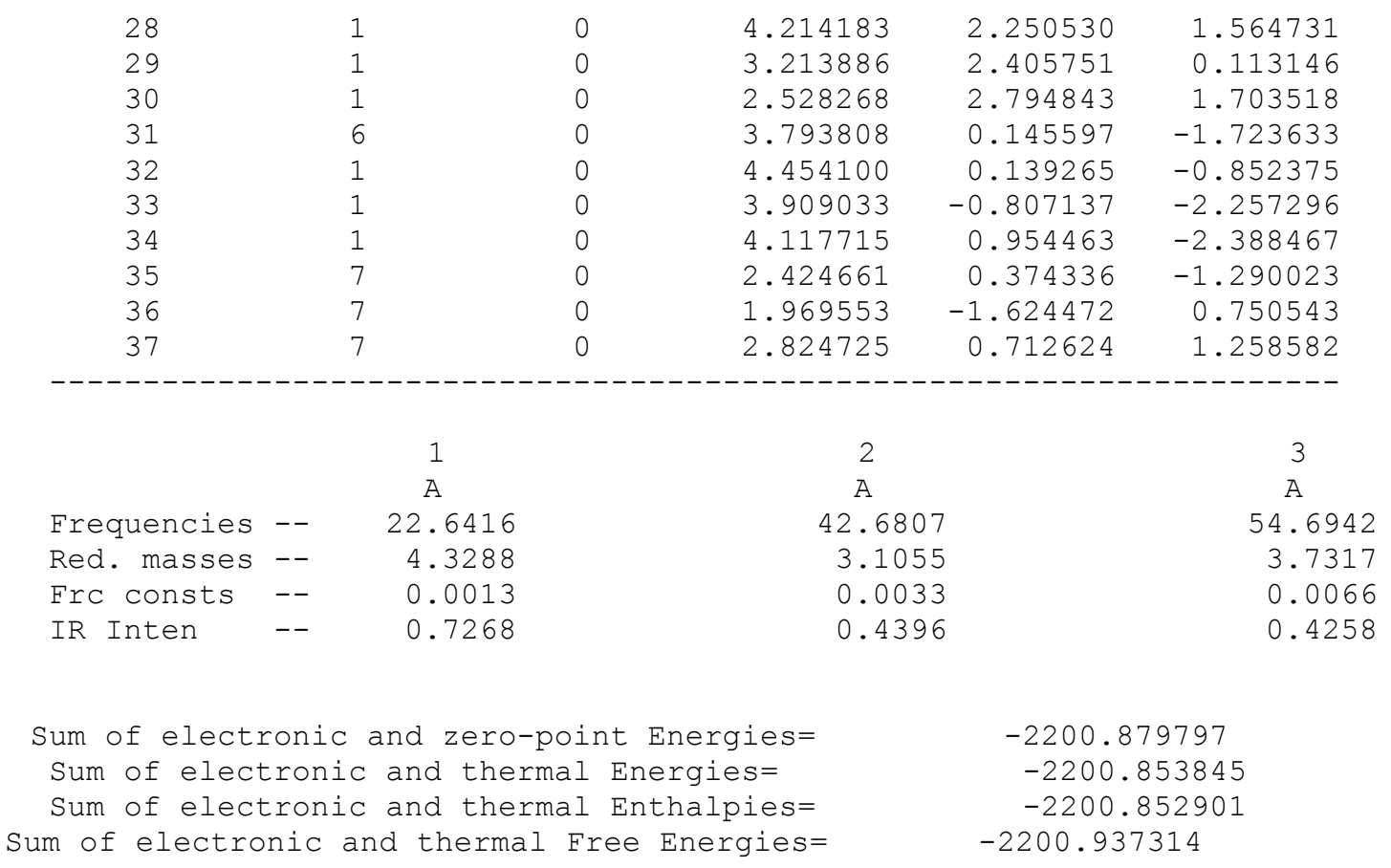

Cartesian coordinates, three lower frequencies and thermochemistry of $\mathrm{InCl}_{3}\left(\mathrm{NH}_{2} \mathrm{CH}_{3}\right)_{2}\left(\mathrm{P}\left(\mathrm{NHCH}_{3}\right)_{3}\right)$ : isomer $\mathbf{A}_{\text {II }}$

\begin{tabular}{|c|c|c|c|c|c|}
\hline Center & Atomic & Atomic & $\mathrm{CoOr}$ & inates (Ang & troms ) \\
\hline Number & Number & Type & $X$ & $\mathrm{Y}$ & $\begin{array}{c}\mathrm{Z} \\
------\end{array}$ \\
\hline 1 & 49 & 0 & 1.015365 & -0.230314 & 0.155966 \\
\hline 2 & 7 & 0 & 1.919761 & 1.947203 & -0.154159 \\
\hline 3 & 1 & 0 & 2.681731 & 1.674962 & -0.776550 \\
\hline 4 & 6 & 0 & 2.511944 & 2.582790 & 1.041362 \\
\hline 5 & 1 & 0 & 3.068877 & 3.491242 & 0.782246 \\
\hline 6 & 1 & 0 & 1.725291 & 2.822120 & 1.758506 \\
\hline 7 & 1 & 0 & 3.185910 & 1.864825 & 1.511707 \\
\hline 8 & 1 & 0 & 1.341767 & 2.619167 & -0.654739 \\
\hline 9 & 17 & 0 & 0.719926 & 0.165604 & 2.532380 \\
\hline 10 & 17 & 0 & 0.133406 & -2.503447 & -0.091162 \\
\hline 11 & 7 & 0 & 0.753962 & -0.283753 & -2.181134 \\
\hline 12 & 6 & 0 & 1.483432 & 0.557220 & -3.140431 \\
\hline
\end{tabular}




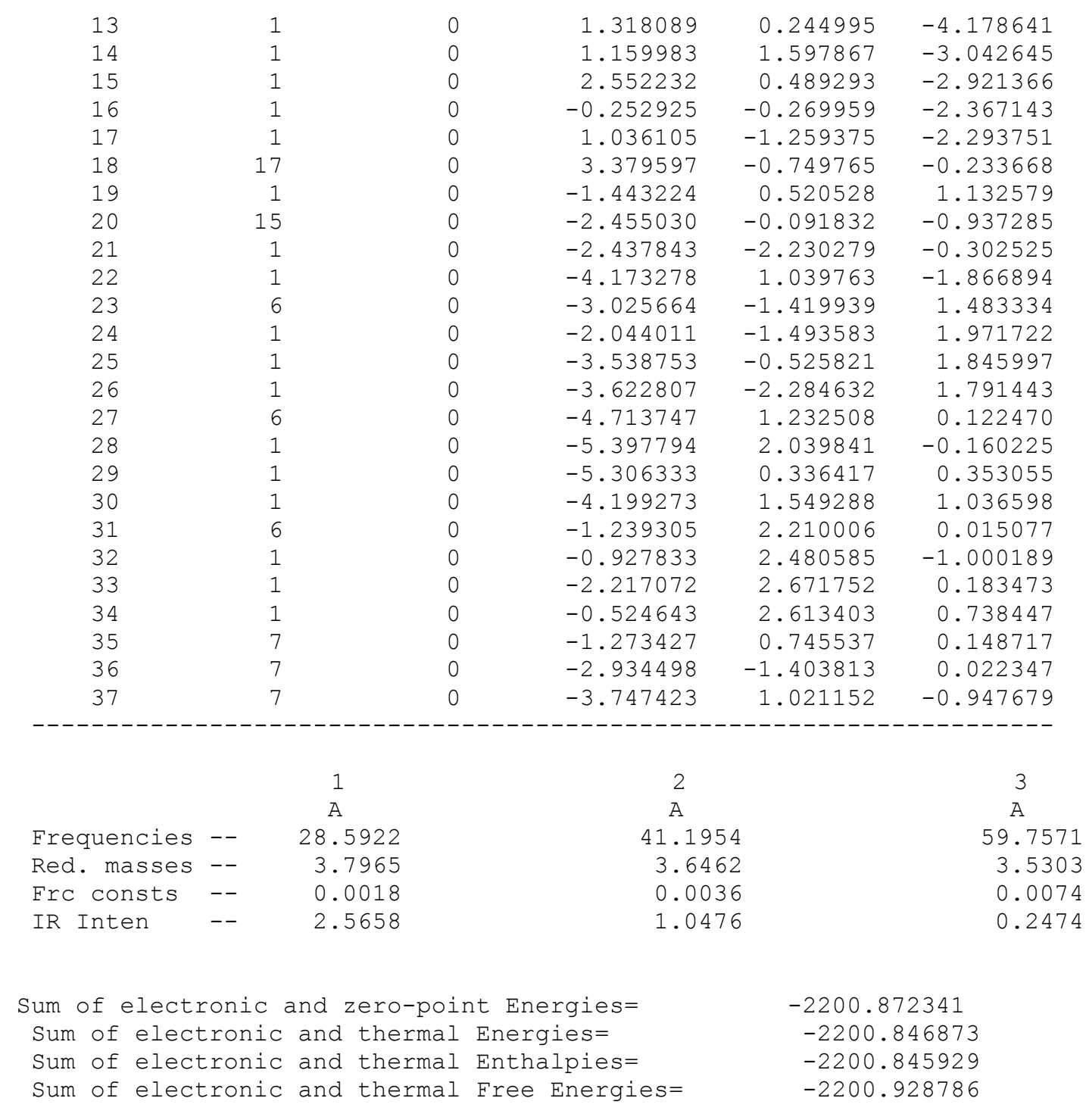


Cartesian coordinates, three lower frequencies and thermochemistry of $\mathrm{InCl}_{3}\left(\mathrm{NH}_{2} \mathrm{CH}_{3}\right)_{2}\left(\mathrm{P}\left(\mathrm{NHCH}_{3}\right)_{3}\right)$ : isomer A III

\begin{tabular}{|c|c|c|c|c|c|}
\hline $\begin{array}{l}\text { Center } \\
\text { Number }\end{array}$ & $\begin{array}{l}\text { Atomic } \\
\text { Number }\end{array}$ & $\begin{array}{l}\text { Atomic } \\
\text { Type }\end{array}$ & \multicolumn{3}{|c|}{$\mathrm{X}_{\mathrm{Y}}^{\text {Coordinates (Angstroms) }}$} \\
\hline------- & -------1 & & 1. & ------- & ---------- \\
\hline 1 & 49 & 0 & 0.964034 & 0.029206 & 0.225694 \\
\hline 2 & 7 & 0 & 2.034011 & 0.608887 & -1.797316 \\
\hline 3 & 1 & 0 & 2.856960 & 0.014207 & -1.695478 \\
\hline 4 & 6 & 0 & 2.491288 & 2.006948 & -1.931934 \\
\hline 5 & 1 & 0 & 3.129382 & 2.142279 & -2.813812 \\
\hline 6 & 1 & 0 & 1.627464 & 2.669789 & -1.996417 \\
\hline 7 & 1 & 0 & 3.050799 & 2.269875 & -1.032603 \\
\hline 8 & 1 & 0 & 1.541747 & 0.315382 & -2.639071 \\
\hline 9 & 17 & 0 & 0.434172 & 2.341488 & 0.744806 \\
\hline 10 & 17 & 0 & -0.060609 & -1.100791 & 2.199815 \\
\hline 11 & 7 & 0 & 1.177916 & -2.224358 & -0.490021 \\
\hline 12 & 6 & 0 & 2.285108 & -2.755323 & -1.296802 \\
\hline 13 & 1 & 0 & 2.263061 & -3.849443 & -1.375827 \\
\hline 14 & 1 & 0 & 2.233249 & -2.340270 & -2.308284 \\
\hline 15 & 1 & 0 & 3.225645 & -2.447483 & -0.833411 \\
\hline 16 & 1 & 0 & 0.277715 & -2.436939 & -0.916865 \\
\hline 17 & 1 & 0 & 1.175653 & -2.658388 & 0.434244 \\
\hline 18 & 17 & 0 & 3.320076 & -0.183830 & 0.908107 \\
\hline 19 & 15 & 0 & -2.333785 & -0.537024 & -0.150206 \\
\hline 20 & 1 & 0 & -2.359090 & 0.130819 & 1.969202 \\
\hline 21 & 1 & 0 & -3.395702 & -0.895838 & -2.127815 \\
\hline 22 & 6 & 0 & -3.329584 & 1.722014 & 1.025327 \\
\hline 23 & 1 & 0 & -2.461738 & 2.389973 & 0.987689 \\
\hline 24 & 1 & 0 & -3.926490 & 1.854123 & 0.118484 \\
\hline 25 & 1 & 0 & -3.954544 & 1.989209 & 1.882766 \\
\hline 26 & 6 & 0 & -4.991933 & -0.964854 & -0.772936 \\
\hline 27 & 1 & 0 & -5.153889 & -2.051603 & -0.755581 \\
\hline 28 & 1 & 0 & -5.168243 & -0.574675 & 0.231145 \\
\hline 29 & 1 & 0 & -5.720530 & -0.511921 & -1.453403 \\
\hline 30 & 6 & 0 & -1.129630 & 0.875170 & -2.048698 \\
\hline 31 & 1 & 0 & -0.650834 & 0.517459 & -2.971646 \\
\hline 32 & 1 & 0 & -2.167329 & 1.118281 & -2.307774 \\
\hline 33 & 1 & 0 & -0.646428 & 1.810411 & -1.741422 \\
\hline 34 & 7 & 0 & -1.016744 & -0.144348 & -0.995664 \\
\hline
\end{tabular}




$\begin{array}{rrrrrr}35 & 7 & 0 & -2.938736 & 0.313605 & 1.148770 \\ 36 & 7 & 0 & -3.641504 & -0.602474 & -1.190064 \\ 37 & 1 & 0 & -2.055713 & -1.760623 & 0.463942\end{array}$

\begin{tabular}{|c|c|c|c|c|}
\hline & & 1 & 2 & 3 \\
\hline & & A & A & A \\
\hline Frequencies & -- & 40.4615 & 49.9581 & 58.6566 \\
\hline Red. masses & -- & 4.7798 & 2.8723 & 2.2932 \\
\hline Frc consts & -- & 0.0046 & 0.0042 & 0.0046 \\
\hline IR Inten & -- & 1.9268 & 0.0119 & 1.4230 \\
\hline
\end{tabular}

$\begin{array}{ll}\text { Sum of electronic and zero-point Energies= } & -2200.868550 \\ \text { Sum of electronic and thermal Energies= } & -2200.843003 \\ \text { Sum of electronic and thermal Enthalpies= } & -2200.842059 \\ \text { Sum of electronic and thermal Free Energies= } & -2200.924818\end{array}$

Cartesian coordinates, three lower frequencies and thermochemistry of $\mathrm{InCl}_{3}\left(\mathrm{NH}_{2} \mathrm{CH}_{3}\right)_{2}\left(\mathrm{P}\left(\mathrm{NHCH}_{3}\right)_{3}\right)$ : isomer A IV

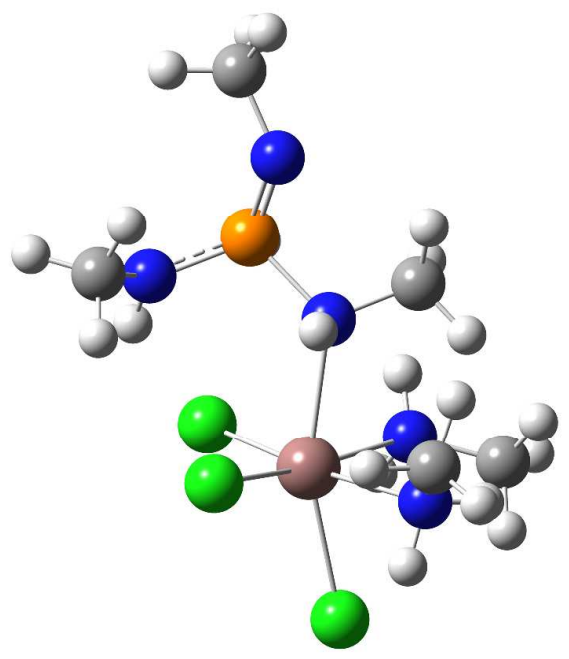

\begin{tabular}{|c|c|c|c|c|c|}
\hline \multirow{2}{*}{$\begin{array}{l}\text { Center } \\
\text { Number }\end{array}$} & \multirow{2}{*}{$\begin{array}{l}\text { Atomic } \\
\text { Number }\end{array}$} & \multirow{2}{*}{$\begin{array}{c}\text { Atomic } \\
\text { Type }\end{array}$} & \multicolumn{3}{|c|}{ Coordinates (Angstroms) } \\
\hline & & & $\mathrm{X}$ & Y & Z \\
\hline & & & --------- & --------- & ---------- \\
\hline 1 & 49 & 0 & -1.022249 & 0.289952 & -0.071773 \\
\hline 2 & 7 & 0 & -1.854283 & -0.969902 & 1.787928 \\
\hline 3 & 1 & 0 & -2.621205 & -0.311382 & 1.945797 \\
\hline 4 & 6 & 0 & -1.129387 & -1.187957 & 3.053541 \\
\hline 5 & 1 & 0 & -1.793736 & -1.533065 & 3.854497 \\
\hline 6 & 1 & 0 & -0.344529 & -1.935888 & 2.911502 \\
\hline 7 & 1 & 0 & -0.670046 & -0.242884 & 3.350480 \\
\hline 8 & 1 & 0 & -2.313699 & -1.829115 & 1.488861 \\
\hline 9 & 17 & 0 & -0.243690 & 1.862724 & 1.597836 \\
\hline 10 & 17 & 0 & -0.207370 & 1.253023 & -2.171474 \\
\hline 11 & 7 & 0 & -1.581993 & -1.459602 & -1.564939 \\
\hline 12 & 6 & 0 & -2.480788 & -2.578076 & -1.240143 \\
\hline 13 & 1 & 0 & -2.775105 & -3.149713 & -2.128221 \\
\hline 14 & 1 & 0 & -1.986924 & -3.259967 & -0.541857 \\
\hline 15 & 1 & 0 & -3.380414 & -2.165591 & -0.776385 \\
\hline 16 & 1 & 0 & -0.745052 & -1.787744 & -2.045193 \\
\hline
\end{tabular}




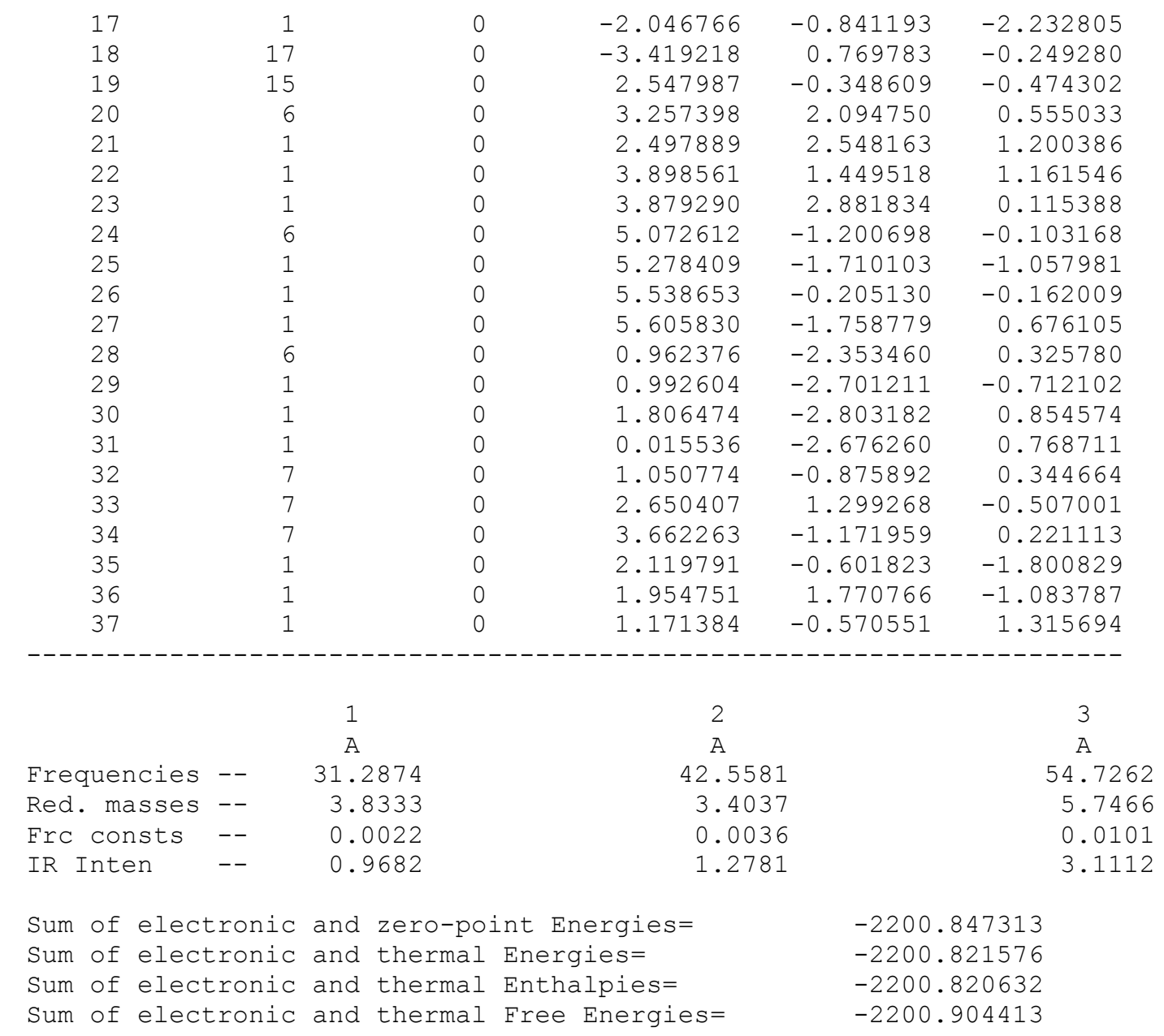

\section{Bibliography}

(1) Frisch, M. J.; Trucks, G. W.; Schlegel, H. B.; Scuseria, G. E.; Robb, M. A.; Cheeseman, J. R.; Scalmani, G.; Barone, V.; Mennucci, B.; Petersson, G. A.; Nakatsuji, H.; Caricato, M.; Li, X.; Hratchian, H. P.; Izmaylov, A. F.; Bloino, J.; Zheng, G.; Sonnenberg, J. L.; Hada, M.; Ehara, M.; Toyota, K.; Fukuda, R.; Hasegawa, J.; Ishida, M.; Nakajima, T.; Honda, Y.; Kitao, O.; Nakai, H.; Vreven, T.; Montgomery, Jr., J. A.; Peralta, J. E.; Ogliaro, F.; Bearpark, M.; Heyd, J. J.; Brothers, E.; Kudin, K. N.; Staroverov, V. N.; Kobayashi, R.; Normand, J.; Raghavachari, K.; Rendell, A.; Burant, J. C.; Iyengar, S. S.; Tomasi, J.; Cossi, M.; Rega, N.; Millam, N. J.; Klene, M.; Knox, J. E.; Cross, J. B.; Bakken, V.; Adamo, C.; Jaramillo, J.; Gomperts, R.; Stratmann, R. E.; Yazyev, O.; Austin, A. J.; Cammi, R.; Pomelli, C.; Ochterski, J. W.; Martin, R. L.; Morokuma, K.; Zakrzewski, V. G.; Voth, G. A.; Salvador, P.; Dannenberg, J. J.; Dapprich, S.; Daniels, A. D.; Farkas, Ö.; Foresman, J. B.; Ortiz, J. V.; Cioslowski, J.; Fox, D. J. Gaussian 09, Revision D.01, 2009.

(3) Perdew, J. P.; Wang, Y. Phys. Rev. B 1992, 45, 13244-13249. 
(4) Hariharan, P. C.; Pople, J. A. Theor. Chim. Acta 1973, 28, 213-222.

(5) P. J. Hay and W. R. Wadt, J. Chem. Phys. 82, 270 (1985). P. J. Hay and W. R. Wadt, J. Chem. Phys. 82, 284 (1985). P. J. Hay and W. R. Wadt, J. Chem. Phys. 82, 299 (1985). 